often containing the clippings from tanneries-an appetizing and digestible addition to the typhoid diet. I should like to add this to Dr. Coleman's list. I have given as much as one pint daily. As gelatin is believed to be antehemorrhagic, it may help to avert this dangerous complication. I want to advise against the use of starches for what seems to me good physiologic reasons, to advocate the use of calves'-foot jelly as an addition to the diet, and to protest against too varied and liberal feeding of patients affected with typhoid fever.

Dr. D. L. PARKer, Detroit: The tendency to more liberal feeding in typhoid is establishing itself rapidly, and it seems to me that the principle that underlies the whole scheme is the return to the mode of living which is natural to the patient, so far as his condition will permit. Certain articles of diet must be eliminated, such as starches, which are digested in the small intestine, as Dr. Walker stated. One of the most important things to remember is that the natural diet contains salt, and, as a rule, the diet given to patients with typhoid fever contains very little salt. For a number of years it has been my practice to see that these patients receive as much salt at least as on an ordinary diet. Another important thing is to have sufficient time between the feedings. It has been found in the forced feeding of tuberculous patients, for instance, that the taking of food at intervals of four or five hours is very much better for these patients than if the meals are closer together. No person here in this room would think of taking food every two hours. I think the giving of food should be at longer intervals. Sufficient time should be given for the digestion of one meal before another is given.

Dr. Woons Hutchinson, New York: Nothing illustrates the progress of medicine better than the treatment of typhoid fever. Over sixty years ago Graves of Dublin chose as his epitaph "He fed fevers." Prior to this, blankets were placed over these patients, they were given very little food; even with high temperatures they were not allowed much water and no fresh air; the windows were kept closed; cold water to drink was regarded as deadly; and only lukewarm slops were permitted; in fact, the patients suffered almost as much from what was done for them as they did from the disease. Six years ago I began to use a liberal diet in my cases of typhoid fever, and the results have been the same as Dr. Coleman's. I had not the courage to carry it so far as Dr. Coleman has done, but the patients were given an abundance of tender meat, broths, jellies, crackers, toast, ice-cream, etc., and the results were excellent, not only as to keeping up the weight and strength of the patients, but also in preventing that condition of collapse after the fever subsided and the violent convalescent appetites which hitherto had eraved such things as corned beef, beans and cold slaw. The patients made more rapid recoveries, had fewer complications and the results as a whole were very good. We think too much of the risk to the damaged intestine from liberal feeding in this disease, and regard typhoid fever as an intestinal disease too exclusively. Typhoid is a general disease, and, as has been shown, those patients who have been fed liberally, instead of suffering more from putrefactive changes in the intestines and tympany, have less of these changes, and fewer complications than those who are underfed. We are coming to see that many of the later symptoms that occur in the disease are due not so much to the actual toxic products of the bacilli as to the poisons generated from the broken-down tissues of the patient. Many of the symptoms occurring late in typhoid fever and $r_{i}$ not so much to the disease itself as to the mis taken method of treatment, among which starvation ranks high. There is a risk in withholding food as well as in giving it.

Dr. Warren Coleman, New York: I did not foresee the na ture of the questions which have been asked me or I should have requested more time of the chairman for my paper. One cannot deal adequately with such a subject as diet in typhoid fever in ten minutes. For lack of time I cannot answer all the questions that have been raised in the discussion. I feel, however, that I must attempt to reply to Dr. Jacobi.

The first thing I would say, and say emphatically, is that I did not experiment with patients in a way that was not thoroughly justifiable. Every increase made in the amount of milk-sugar was carefully controlled by observation in the hospital and by examinations in the laboratory of experimental pathology. Every increase made in the amount of fat was controlled in the same fashion. When there was reason even to suspect that the food was not agreeing with a patient, that particular article of food was stopped or diminished in quantity. I think that Dr. Jacobi perhaps has gained a wrong impression with regard to the amount of cream given. The usual quantity was one pint; sometimes as much as a quart; and in one or two instance even more. I did not observe any digestive or intestinal disturbances in any patient who was fed on this relatively large amount of cream except once; diarrhea occurred in that instance. The cream was stopped and at once the diarrhea ceased. Cream was not given again to this patient. The stools of all the patients were watched very carefully. There was no evidence that the cream was not, for the most part, utilized.

I am convinced that the principal question regarding the typhoid diet is whether it is desirable to let a patient live on his own tissues when it is possible to protect his tissues by giving him enough food. I have not yet worked out all the details of the diet. It has been estimated that gelatin may replace protein to the extent of one-fifth of the daily need of nitrogen. I started out to determine whether by giving a patient a sufficient number of calories to cover his expenditures, I could protect the body tissues. This was accomplished. In future I shall work in part on more practical problems, such as the varieties of food which may be given and the proper ways to prepare them. I did not follow the plan of giving large amounts of water, but was guided chiefly by the desires of the patients.

The patients are weighed on a long table, which, when placed on the platform of the scales, corresponds with the height of the bed. The weight is obtained without more disturbance to the patient than moving him from one side of the bed to the other.

\section{INTRADURAL TUMOR OF THE MID-DORSAL CORD}

OPERATION: COMPLETE RECOVERY OF SENSATION AND PARTIAL RESTORATION OF MOTION *

JULIUS GRINKER, M.D.

Professor of Nervous and Mental Diseases in the Chicago Postgraduate Medical School, Assistant Professor in Clinical Neurology, Northwestern University Medical School. Consulting Neurologist to the Cook County Hospital, Chicago, the Cook County Hospital for the Insane and the Cook County Infirmary at Dunning, Ill. CHICAGO

The era of spinal tumor surgery began in $188 \%$ when Gowers ${ }^{1}$ correctly diagnosed and Horsley successfully removed a tumor from the mid-dorsal cord. The operation was followed by almost complete recovery of sensation and motion. Since the publication of this remarkable case, in 1888, neurologists and surgeons have vied with each other in their efforts to improve the neurologic and surgical technic of the diagnosis and surgery of spinal tumor.

Although many patients have been rescued from early graves and others have been restored to perfect health from a state of invalidism, yet the total number of complete and partial recoveries is not so large as to make the report of a single case superfluous. The diagnosis in some instances is extremely easy and certain, while in others it can never reach beyond a probability. The difficulties in diagnosis have been sufficiently set forth in the instructive article by von Malaisé, ${ }^{2}$ the complete monograph of Bruns, ${ }^{3}$ the lucid reports of $\mathrm{F}$.

* Read in the Section on Nervous and Mental Diseases of the American Medical Association, at the Sixtieth Annual Session, held t Atlantic City, June, 1909

1. Gowers and Horsley: Med.-Chir. Tr., 1888, p. 407.

2. Von Malaisé : Zur Differentialdiagnose der extra- und intra-

medullären Tumoren, Deutsch. Arch. f. klin. Med., 1904, Ixxx, 143.
3. Bruns: Die Geschwülste des Nervensystems, 1907. 
Schultze, ${ }^{4}$ Oppenheim, ${ }^{5}$ Fedor Krause, ${ }^{6}$ and a number of American and English observers.

In my remarks at the conclusion of the following case report I shall briefly allude to the literature bearing on cases of spinal tumor in which operation has been performed.

\section{REPORT OF CASE}

Patient.-B. F., a working girl, aged 23, was first seen at the request of Dr. A. Goldspohn on Dec. 17, 1906.

Family History.-The parents were living and well; the grandparents on the mother's side died of old age; on the father's side they lived to middle age; their death was due to causes other than tuberculosis, malignancy, or vascular accident. An only brother and a sister were healthy. The family was remarkably free from functional and organic nervous dis. ease.

Personal History.-The patient was born in normal labor and during infancy and early childhood had been free from serious disease. With the exception of an attack of typhoid at 12 , measles and pertussis at 13, her health had been good until the beginning of the present illness. Her menses were regular, habits correct; there was no trauma or evidence of venereal infection.

Onset and Course of Disease.-Early in 1906 (January or February) the patient began to experience attacks of pain in the right hypochondriac region, which subsequently became more or less persistent. Occasionally the pains radiated into the epigastrium and produced a sensation of nausea, accompanied with eructations. It was the latter circumstance which first induced her to seek medical assistance. For some time she was treated for dyspepsia and neuralgia. Later an osteopath was consulted who endeavored to reduce a supposed cisplaced vertebra. In spite of all treatment, however, the symptoms continued to progress. The pains, which were at first almost entirely confined to the right half of the body, soon began to invade the left side, art in less than two months had nearly encircled the trunk at a height of one or two fingerbreadths below the nipples. Though there was considerable variation in the intensity of the pains, they were never entirely absent. The upper portion of the trunk, the face and upper extremities were at no time the seat of sensory disorder, but several weeks after the beginning of the disease, fatigue and numbness were complained of in the lower extremities, and these sensations had a tendency to become more or less constant. On Sept. 23, 1908, after having retired for the night, the patient awoke feeling numb and stiff in the left leg from the knee downward. When she stepped out of bed to ascertain if she could still walk, the discovery was made that the left leg dragged and was partially paralyzed. There was considerable improvement in this limb on the following day, but the right leg had meanwhile become similarly affected; the latter grew rapidly worse and within three days was paretic. One week after these motor disturbances a feeling of tightness appeared about the waist and all sensation was abolished below the umbilical line. The sphincters were somewhat affected. The patient could then still walk without support, but was obliged to take rather small steps, as the feet seemed glued to the floor. At this period of the progress of the case she en. tered a hospital where she received vigorous antispecific treatment for about ten weeks. It was while under such treatment, about three weeks after the fi..st motor symptoms had appeared, that the left and, soon afterward, the right leg became completely paralyzed. With the paraplegia there appeared more marked muscular twitchings and jerkings, which had for some time previously been the cause of considerable discomfort. In addition there were burning sensations in the paralyzed parts. The bladder and rectum subsequently became paralyzed. Her condition continuing to grow worse, the relatives caused a transfer to the Evangelical Deaconess' Hospital, where she became a patient of Dr. Goldspohn, who kindly referred the case to me for an examination. This was made on Dec. 16, 1906, and the following notes taken:

4. Schultze, F.: Zur Dlagnose der Operabilität der Hirn- und Rückenmarkstumoren und Operationserfolge bel denselben, Mitt. a 5. Oppenheim : Beiträge zur Diagnostik und Therapie de Geschwülste im Bereich des centralen Nervensystems, 1907. 6. Krause, Fedor: Zur Kenntniss der Rückenmarkslähmungen,
"Examination.-The patient, a well-developed girl, weighing about 150 pounds, of average height, occupies a recumbent posture and answers questions intelligently. But for the occasional demonstrations of pain caused by recurrent muscular spasms in the lower extremities, she gives one the impression of perfect health. Examination reveals normal findings in heart, lungs and abdominal viscera; the pulse is soft, regular and 75 beats per minute. Blood and urine normal. Pupils are equal, respond to light and in accommodation. Vision is unimpaired and eyegrounds appear normal. Glandular enlargements or evidences of neopiasm can not be discovered on her body.

"Motion: Eyes, face, neck and upper extremities are not involved; in marked contrast with these organs are the parts below the nipple line; here everything seems lifeless. The abdominal muscles are paretic and there is a condition of "leadpipe" rigidity in the spastic lower extremities. From time to time the legs are seen to draw up and slowly to relax; voluntary control over the muscles is completely lost. The sphincters are distinctly paretic. The bladder empties itself periodicaliy witnout the patient's knowledge. The bowels are absolutely constipated; several enemas are usually required to cause a partial evacuation.

"Reflexes: Normal in eyes, face and upper extremities. Abdominal reflexes are absent. The patellar and ankle-jerks are pathologically exaggerated; there is distinct bilateral rectus and ankle clonus. Babinski, Oppenheim and Gordon signs are promptly obtained.

"Sensation: 1. Tactile sensation is abolished up to a point which corresponds on Seiffer's charts to the space midway between the fifth and sixth dorsal segments on the right and to about the sixth segment on the left side anteriorly (Fig. 1). Posteriorly tactile sensation is lost up to about a line indicating the sixth dorsal segment on the right and to about onehalf segment below this on the left side (Fig. 2).

" 2 . In a small strip below the upper limit of tactile anes. thesia pain and temperature sense are still preserved (areas shaded lightly in Figs. 1 and 2 ).

" 3 . There is a somewhat larger area below the one last mentioned in which the pain sense is still preserved, while other sensory qualities are lost (circles in Figs. 1 and 2). Sensation seems to have suffered first and most in tactile conduction, then the temperature qualities appear to have yielded and last of all the pain sense has succumbed."

Diagnosis.-A history of unilateral pain gradually becoming bilateral, followed by motor paralysis of first one lower extremity, then of the other, with sphincter and sensory paralysis added, presented the classical symptom-complex of spinal tumor. The negative findings above the line of beginning anesthesia certainly excluded diffuse cerebrospinal disease. The relatively slow evolution of symptoms was against the diag. nosis of acute transverse myelitis and in favor of slow compression of the cord by tumor. Syphilis and tuberculosis had still to be considered. But there were no stigmata of con. genital or acquired lues and no evidence of tuberculosis anywhere on the patient's body. Neither was there a history of trauma or of infection. Having decided that there was a tumor of the cord, the next task was to localize it. This was comparatively easy. Sensory disturbances of any kind being found opposite a line midway between the fifth and sixth dorsal segments, the upper end of the neoplasm was probably situated opposite the spine of the third dorsal vertebra.

In the determination whether the tumor was extradural, in. tradural or medullary in character, I was influenced by the following considerations:

1. There were no neoplastic formations anywhere in the body; there was no deformity of, or tenderness in the vertebræ. The pains were, in the beginning at least, not agonizing, constant or of long duration. These negative findings spoke strongly against the existence of an extradural tumor.

2. The early presence of root irritation (pain) and at the same time the absence of cord symptoms make the diagnosis of intradural tumor at least improbable; for in such tumors the rule is for cord symptoms to appear early and for pain to come late.

My diagnosis was: Spinal tumor, probably intradural and situated at or about the spine of the third dorsal vertebra.

Immediate operation was advised. 
My colleague, Dr. Goldspohn, concurred in the diagnosis and was ready to operate, when for some unknown reason the patient's friends moved her to Wesley Hospital and entered her there as a ward patient. While at this hospital she was assigned to Dr. S. C. Plummer, the surgeon on service, who kindly referred the case to me for a neurologic opinion. After a re-examination, finding that no material change had occurred in her condition, I again concluded that a laminectomy was indicated. Dr. S. C. Plummer performed the operation on Jan. 4, 1907. He has kindly permitted me to abstract the following notes from his surgical report of the ease before the Chicago Surgical Society, May 8, 1908 :

Operation.-Patient was placed in the semiprone position on the left side. Ether anesthesia was used. The incision was made in the median line of the back, beginning just below the seventh cervical vertebra and extending downward to the seventh dorsal spine. The muscles were cut away from the

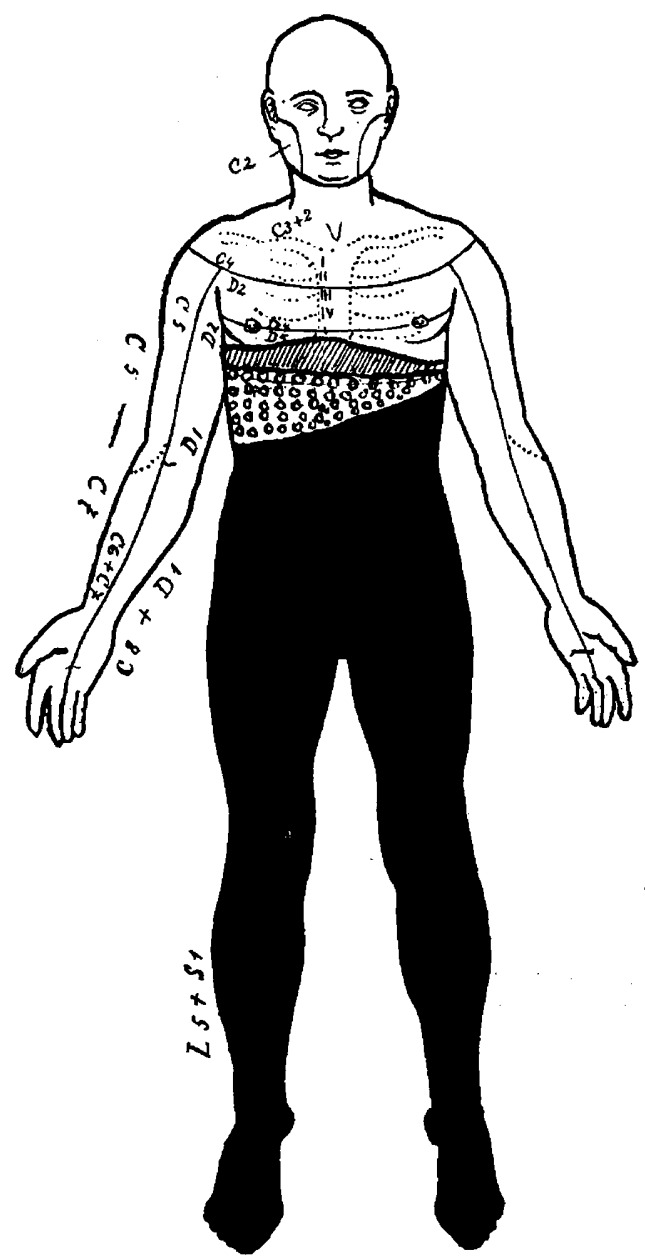

Fig. 1. appeared normal in color; nothing abnormal could be felt on palpation. Pulsation seemed normal, but it was stronger in the upper third than in the lower two-thirds. This extensive exposure of the dura is explained by the circumstance that, having uncovered three cord segments and finding the dura seemingly normal, we believed an error in localization had been made. It was therefore decided to snip off another spine. When consequently the fifth vertebral spine had been removed and the dura still appeared normal, it was thought best to open it and search for the tumor. The patient's head was now somewhat lowered and the dura opened in the median line. Opposite the third dorsal spine a tumor was found lying between the membranes and the cord posteriorly and somewhat to the right. Using the handle of the knife this was easily delivered and the small pedicle broken off. While its exact attachment could not be definitely ascertained, it appeared to spring from the inner surface of the dura. The anesthetist

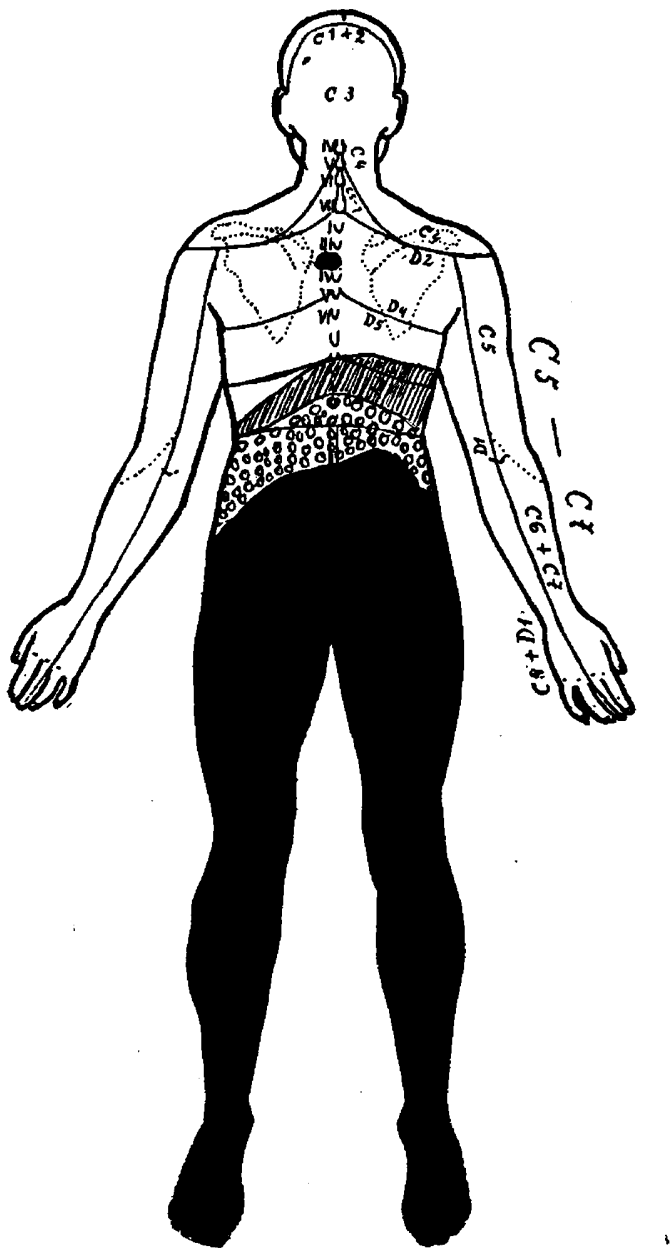

Fig. 2.

Figs, 1 and 2--In both figures, the biack space signifies total loss of all qualities of sensation: the circles indicate loss of thermal and tactile sensation; the shading denotes mere loss of tactile sensation. In Figure 2 (the back view), the heavy dot shows the highest border of the tumor.

sides of the spinous processes from the first to the sixth dorsal vertebræ on the left side. Several vessels were clamped and ligated, and a hot laparotomy sponge was packed into the wound, while on the right side the muscles were separated in a similar manner. Hemorrhage having been checked, the vertebral grooves were now cleared with a chisel by using the spinous processes as a fulcrum and pushing the tissues away from the laminæ. The spinous process of the fifth dorsal vertebra was now cut off with a bone-cutting forceps, and the ligamentum subflavum between it and the fourth dorsal vertebra severed with a knife. A special laminectomy forceps was used to cut away part of the laminæ of the fourth dorsal vertebra and the remainder was removed with the rongeur forceps. The dura, which now lay exposed from the lower border of the first to the upper border of the sixth vortebra, noticed that the pulse, which up to this time had been but little above the normal, suddenly became very fast and diffieult to count. The dura was now closed with a continuous suture and the muscles brought together with interrupted catgut sutures, leaving a space for a gauze drain down to the dura at the upper and lower extremities of the wound. The skin was closed with silkworm-gut sutures, a secondary suture being used at each end of the drain. In forty-eight hours one gauze drain was removed and in seventy-two hours the remaining one, secondary sutures being tied after removal of the drains. Aseptic healing throughout.

Pathologic Report.-When examined macroscopically the tumor appeared reddish-yellow, was rather soft in consistency and measured $3 \mathrm{~cm}$. in length, $0.8 \mathrm{~cm}$. in its widest diameter and $0.2 \mathrm{~cm}$. in thickness. The microscopic examination was 
made by Prof. F. R. Zeit, of the Department of Pathology at Northwestern University Medical School, who kindly reported on the tumor and pronounced it a typical fibromyxoma.

Postoperative History.-Immediately after operation the patient complained of severe pain in the back and over the entire lower half of the body. The pains somewhat subsided after two or three days and then became localized in the back and Iegs, where they remained for several weeks. Improvement occurred in the following order: Within twenty-four hours after operation the temperature sense showed signs of recovery; it was noted that hot-water bottles applied to the feet caused a disagreeable sensation. In less than a week after the operation the patient experienced a feeling of discomfort from a full bladder. Within two weeks she could distinguish between extremes of temperature. After three weeks painful stimuli, such as pin-pricks, were perceived as disagreeable. Tactile sensation and fine discrimination, as well as correct localization, of touch were very slow in returning. It was probably one year before the patient's sense of position and fine localization of touch were restored to normal. Although perfect recovery of all forms of sensation occurred within the period stated, it was quite different with motion. It will be recalled that the patient was completely paraplegic at time of operation; all motion in legs and toes was entirely abolished. Signs of return of motion appeared about six weeks after opertion. She could then flex the left big toe; somewhat later she gained control over the small toes of the left foot. Slowly and only after many months did a slight degree of motion return in the feet, but the thighs and legs remained spastic. For a long time one could still see the spasmodic movements of the legs on the thighs, which would only with great difficulty be passively extended. This condition gradually improved, but the patient never walked again.

Repeated examinations, made at intervals of three months each, revealed practically the findings as stated.

An examination made Feb. 20, 1909, showed: Good physical condition. Sensation and sphincters perfect. In the sphere of motility considerable improvement was noted; the patient could now use the feet and legs in operating a sewing machine several hours in succession. She was also able voluntarily to flex the legs againsi the thighs, full length. Flexion and extension of feet and toes could be performed fairly well. With some effort extension of the left leg was possible with the thigh flexed; extension of the right leg with the thigh flexed was only partial. For a few moments she could stand when supported by her upper extremities. She had not attempted the use of crutches because of her present faith in Eddyism, which forbids the use of such physical artificial aids.

Examination on May 22, 1909, yielded practically the same findings as previously. She had been persuaded to try crutches, but they did not sustain her weight, owing perhaps to her inability to extend the legs completely, slight contractures having formed in the knee joints. By means of orthopedic measures $I$ believe her condition may be considerably improved.

\section{REMARKS}

The case presented a typical classical picture of intradural tumor in the upper dorsal cord, not unlike the first case with successful operation by Victor Horsley. ${ }^{1}$ In that case, however, the neuralgie state was protracted over a period of four years, from 1884 to $188 \%$. In this case the period of root-irritation lasted seven or eight months. 'The pains, for a time at least, were distinctly localized on the right side, and, as the tumor enlarged in width, pains also appeared on the left side. Fight months later cord symptoms were very much in evidence, and, as in other cases, the most vulnerable motor tracts suffered before the more resistant sensory strands. A further similarity of this case with that of GowersHorsley is seen in the fact that the tumor on microscopic examination proved to be a fibromyxoma; but in this case, unlike theirs, the tumor had grown rapidly.

Considering the final outcome, how should this case be classified?
According to Collins, ${ }^{7}$ it will have to be classed with the partially successful cases. In Collins' excellent article on spinal cord tumors he notes that an operation is considered successful when there is cessation of pain and recovery of motor power; partially successful when there is relief from pain, cessation of progress of the case, and slight regain of motor power; unsuccessful, when followed by death within a few weeks. This patient showed complete recovery of sensory functions, some regain of motor power and no return of symptoms two and a half years after operation.

Had the case been diagnosed before degeneration occurred in the motor tracts it would in all probability have found a place among the completely successful cases. From the history it is apparent that a positive diagnosis of spinal tumor could have been made at least three months before operation, yet ten weeks had been lost in treating the patient for syphilis. This is all the more regrettable since we know that gumma of the cord membranes is rare, and when found should be treated surgically the same as other tumors.

In a perusal of the recent literature on spinal tumor we discover-in marked contrast with the earlier publications-that cases are now diagnosed and patients operated on much earlier than formerly, with the inevitable result that the percentage of recoveries is becoming larger. Recent conservative estimates place the proportion of partial and complete recoveries after operation at 50 per cent. This has become possible only through the combined efforts of neurologists and surgeons, the former of whom have made spinal localization comparatively easy, while the latter have simplified and improved the surgical technic.

The wide interest which is at present being taken in surgical neurology is largely a result of the awakening to the possibilities of surgery, particularly of the periphcral nerves and spinal tumors. Already in $1895 \mathrm{M}$. Allen Starr, ${ }^{8}$ after analyzing 123 tumors of the cord, argued that an early diagnosis of spinal tumor was possible; that removal could be accomplished without injury to the cord; and that the operation itself was not one of great danger. He considered that in nearly 75 per cent. of cases spinal tumors could be operated on successfully and he expressed the opinion that future statistics should show recovery in a much larger proportion of the cases than they did at that time. Considering that Bruns $^{9}$ in $189 \%$ could collect only 20 cases of spinal tumors operated on, and Bregman $^{\mathbf{1 0}}$ as late as 1906 could find only 50 cases of operation, it was remarkable that Stursberg ${ }^{11}$ in his report could make the statement that up to 1908 he had already been able to collect 119 observations of extramedullary tumors operated on, in which diagnosis was proved either by operation or by autopsy. In the same year E. Flatau and N. Zylberblast, ${ }^{12}$ who conjointly reported a case, estimated the total number of published cases of extramedullary tumor with operation to be 136 , of which number 106 were intradural or extradural tumor, while 29 were cases of tumors originating from or extending to the vertebræ. It is noteworthy that Schultze ${ }^{4}$ alone in 1907

7. Collins, J.: Spinal Cord Tumors, Med. Rec., 1902, p. 882. 8. Starr, M. Allen: Tumors of the Spinal Cord, Am. Jour. Med. Sc., 1895 , p. 614

9. Bruns : Die Geschwïlste des Nervensystems, 1897. 10. Bregman: Ein Beitrag zur Klinik und zur operativen Behandlung der Rückenmarksgeschwülste, Deutsch. Ztschr. f. Nervenh., 906 , XXxi, 68

11. Stursberg: Die operative Behandlung der das Rückenmark und die Cauda comprimirenden Neubildungen, Centralbl. f. d Grenzgeb. d. Med. u. Chir., 1908, Nos. 3 and 7 .

12. Flatau, E. and Zylberblast, Frl. N.: Beitrag zur chirurgischen Behandlung der Rückenmarkstumoren, Deutsch. Ztschr. f. Nervenh., 1908 , Xxxv, 334 . 
could report on 14 cases with operation, in which number 6 patients made perfect recoveries and 2 showed improvement. Oppenheim ${ }^{5}$ in the same year reports practical recovery in 4 out of 9 cases with operations in which he had made a correct localizing diagnosis.

In spite of the great activity displayed in this branch of surgery during the last ten years, the total number of cases with operations up to date has not exceeded 150. And of this number the percentage of recoveries has only risen in the hands of the most expert surgeons when working conjointly with neurologists.

As for the total number of complete recoveries in cases with operation, Harvey Cushing, ${ }^{13}$ who reports a case of his own with complete recovery, in 1904, could find only 10 other successful cases. But already in 1908 R. T. Williamson ${ }^{14}$ found 51 published cases of meningeal spinal tumor in which operation was successful and had been followed by complete or almost complete recovery from spinal symptoms.

Several reasons have been advanced for the few recoveries so far recorded. One is that spinal tumor is not always easy to diagnose and localize; a failure to find the tumor usually means death by further inaction. A second important cause for failure is the discovery on the operating table that a correctly localized tumor is inaccessible, hence irremovable, as are most intramedullary and vertebral tumors. And, last but not least, the danger to life during and after operation is still great. While, therefore, by no means underestimating the dangers and pitfalls of surgical interference I am in thorough agreement with those who recommend exploratory laminectomy even in those instances in which the diagnosis is only probable. There should be less unwillingness on the part of the patient to consent to an operation if he is told that inaction will almost invariably destroy his life.

100 State Street.

\section{ABSTRACT OF DISCUSSION}

Dr. Pearce Bailey, New York: I think we have a good many lessons yet to learn in the surgical treatment of spinal cord tumors. If one reads the list of cases in which the patients were successfully operated on, and those in which the operation has not been successful although the tumor has been found, the conclusion is inevitable that we ought to have a very much higher percentage of cures in these cases than we have at present. Many patients die of shock and sepsis and, I believe, from loss of cerebrospinal fluid. I am much in favor of doing operations in spinal cord tumors with the patient's head down, so that the loss of cerebrospinal fluid can be controlled. In a patient operated on in St. Luke's Hospital a short time ago, by Abbe, the tumor was found where we thought it would be. The operation was skillfully performed. There is no better operator for spinal cord tumors than Dr. Abbe; the operation took only 40 minutes; there was no hemorrhage, no infection, and yet there was considerable loss of cerebrospinal fluid. The operation was done on a horizontal table. Within a few hours the temperature began to rise and rose steadily to 103 degrees and $105 \mathrm{de}$ grees, and within about 18 hours after the operation the patient died with a temperature of 107 degrees, with absolutely no infection and no cause discoverable except the loss of cerebrospinal fluid. I think this operation is a grave and serious one and very hazardous to life, and I think it should be undertaken with every precaution.

Dr. Grinker says that the surgeon in his case started by taking out 5 laminæ. I do not see any reason for that. I try to get the surgeons who operate for me to limit themselves in the start, if they will trust my localization, to

13. Cushing. Harvey : Intradural Tumor of the Cervical Meninges, Ann. Surg., 1904, xxxix, 934.

14. Williamson, R. T.: Diseases of the Spinal Cord, 1908. two laminæ. And then it is easy enough to take out others if necessary. At first remove two laminæ, and then examine, and possibly the tumor will be found in one extremity. Then it is time enough to take out the extra lamina; and 3 is generally enough for the expression of the tumor. I think it is very important, because many patients die of shock, and the operation should be limited to as small an area and done as quickly as possible. In regard to localization I have found useful in the dorsal region Horsley's old rule of $10 \mathrm{~cm}$. above the superior line of anesthesia, however slight the anesthesia may be. We seldom find in spinal cord tumors the profound anesthesia we find in transverse lesions from other causation, and consequently $I$ take as my limiting line the slightest blunting of anesthesia. I think also that we should not refuse this operation simply because we are unable to decide whether the tumor is in the vertebræ or extradural or intradural, or even intramedullary. I know of no absolute meane of deciding definitely on any one of these conditions. Thermoanesthesia is no index. Over and over again, meningitis, tumors of the vertebra and tumors of the membranes have caused dissociation of anesthesia. I have seen many operations given up because the anesthesia was disassociated. I think it is a mistake. Even if exact localization can not be made I think the operation should be undertaken promptly and independently of the situation of the tumor with reference to the cord.

Dr. Max MaIlhouse, New Haven: I want to endorse Dr. Bailey's statement with regard to the dissociation of sensation being due to spinal cord or spinal tumors. I recently had a case of recurrent carcinoma about and in the spine, which resulted in the spine forming a knuckle and pushing the cord to one side, in the middle cervical region, in which an early symptom was disassociation of sensation in addition to severe pain and marked spasm of the muscles, so intense that the case at first resembled a case of spondylitis; but one of the early symptoms, as I said before, was disassociation of sensation; and this disassociation, preservation of tactile sense, with diminution of pain and temperature sense, was very striking in this case.

Dr. Charles W. Hitchcock, Detroit: I recall an interesting case which was presented to the Detroit Neurological Society last November by Drs. Inglis of Detroit and Klingmann of Ann Arbor, the findings of Dr. Inglis, who had seen the case, not being known to Dr. Klingmann. Dr. Klingmann accurately diagnosed the segments involved and the position of the tumor, and it was my good fortune to be present a week later at the operation performed by Dr. Max Ballin of Detroit. As in the case reported, too low a laminectomy was I_ade in the hope of finding the tumor lower down, neglecting Chipault's rule of subtracting two from the determined segment, in the upper dorsal region, to find the exact spinal vertebra. The tumor was found just as Dr. Klingmann had diagnosed it, involving the sixth, seventh, and eighth dorsal seg. ments. The tumor was removed, the patient did well, and the sensory and motor symptoms were both very much improved at the last report.

Dr. M. Allen Stark, New York: My experience in spinal cord tumors is quite extensive, and I consider the diagnosis a comparatively easy one. I think that the typical symptoms. appear so definite and distinct in these cases that there is hardly any danger of mistaking them for anything else. Early operation is essential and in two cases recently the question of whether the patients were syphilitic was decided by the Wassermann test. Finding the cerebrospinal fluid and blood absolutely negative, we avoided the supposed necessary delay of attempting to use mercury and iodid, as has been done so often. In my last case I first saw the patient on Saturday afternoon and the operation was done the following day. The tumor was found. The patient is recovering nicely and regaining power over and control of bladder and rectum that were absolutely lost when I saw her. The paraplegia is passing off. The excessive pain is, of course, the very most important symptom in these cases. I know of absolutely no condition resembling it in all respects except caries of the spine, and that, of course, can often be ruled out by physical examination, or certainly by an $x$-ray examination. 
The point is well taken by Dr. Bailey that the success in the operative interference with these tumors depends, first, on the avoidance of shoek; secondly, the avoidance of hemorrhage; thirdly, the rapidity of the operation, and, fourthly, the limitation of the opration, so far as possible, to the essential parts. There is absolutely no necessity of making very large incisions in these cases. Horsley has laid down a reliable guide; it consists of measuring 4 inches above the level of the upper faintest trace of sensory disturbance, and by that I think the sensations should be tested always from below upward. I wish to make it very clear that a patient who is tested from above downward does not notice the little disturbance of sensation, a little loss, as you go down, but a patient with a disturbance of sensation if you get to the lower part and come up will immediately notice the improved sensation; 4 inches above the upper line you are pretty sure to find your tumor. Therefore, I think two laminæ are ample, the surgeon always having made his preparations to lay bare the lamina above if he fails to find the tumor under the two laminæ that are taken out. The tumor can not be taken out by simply dividing one lamina; two must be removed in order to give room for the enucleation of the tumor. So far as I have seen, these tumors have to be carefully elevated and cnucleated in their removal. It seems to me that the progno sis in these operations is constantly becoming better.

Dr. Julius Grinker, Chicago: Much as we may dislike it, surgeons are still laboring under the antiquated idea that myelitis is largely syphilis of the cord, and not until they have subjected the patient to a course of rigorous antispecific treatment do they decide to operate. I believe that we should urge exploratory laminectomy in suitable cases, and that we should discourage the routine administration of antisyphilitic remedies, which are useless in spinal tumor and merely permit irreparable damage to be done to the cord structures, as in the case which I reported. I fully agree with Dr. Bailey that as few laminæ as possible should be removed, but certain exigencies will necessitate the removal of several laminæ. I think the danger from loss of support to the spinal column has been exaggerated. In my case four laminæ were removed, yet there is not the slightest sign of wakening in the spinal column.

\section{THE ENDOMETRIUM AND SOME OF ITS VARIATIONS*}

\author{
WILLIAM S. GARDNER, M.D. \\ AND \\ EMIL NOVAK, M.D. \\ BALTIMORE
}

It is surprising to note how few sharply defined and generally accepted facts have been crystallized out of the great amount of work which has been done on the histology and pathology of the endometrium. The numerous classifications of endometritis, for example, are ample evidence that none is entirely satisfactory, while some, as a matter of fact, are little short of absurd. Particularly unfortunate have been the attempts to classify endometritis along clinical lines, and it seems to have been decided that the most satisfactory or, at any rate, the least unsatisfactory basis for classification is a histologic one.

In this brief communication we propose first to present the results of our studies on the normal histology of the endometrium, with especial reference to the modifications thereof which are associated with the menstrual cycle. It is not our intention to take up a consideration of the various diseases of the endometrium, except in so far as our conception of these diseases may be influenced by our knowledge of normal variations in the structure of the uterine mucosa.

* Read in the Section on Obstetrics and Diseases of Women of the Amelican Medical Association, at the Sixtieth Annual Session, held at Atlantic City, June, 1909 .
Our general study is based on the microscopic examination of the uterine mucosa from over 200 cases in the gynecologic clinic of the Baltimore City Hospital during the past three years. In the majority of these cases the mucosa was obtained by curetting, in a smaller number by extirpation of the uterus for one reason or another. In all cases the material was fixed immediately after removal, and the stain employed, with few exceptions, was the ordinary hematoxylin-eosin method.

In order to study the menstrual phenomena there was selected from the entire number of cases a series of 50 in which an accurate record of the menstrual history was available, including the date of the menstrual onset and usually of the termination of the period preceding the operation. In some of this group the material was obtained by routine curetting in connection with plastic operations of one form or another, there being no evidence of uterine disease. In other cases the mucosa was obtained from cases complicated by various associated conditions, such as myoma, salpingitis, displacement, etc., although no case was admitted to the series unless the regularity of the menstrual cycle was undisturbed.

In the main, therefore, the conditions surrounding our work have been similar to those under which was carried on the valuable work of Hitschmann and Aderi? to which we shall have frequent occasion to refer.

In order to appreciate the change which recent inves tigations have produced in our conception of the normal structure of the endometrium one need only read the descriptions contained in the various text-books of gy ecology and anatomy. In the usually accepted sense the endometrium is the corporeal portion of the uterine mucosa, i. e., the portion above the level of the internal os. It is usually described as consisting of a surfade. epithelium, glands, and an interglandular tissue, or stroma. The epithelium is of the ciliated colurarar variety, differing from that in the cervix in that the: cells are not so tall and slender, that the nuclei take on a paler stain and are situated near the center of the cells instead of near the basement membrane, and that the protoplasm takes on the easin stain, while that in the cervix not infrequently takes a pale hematoxylin stain on account of the excessive amount of muculs which it contains. The glands are described as being of the simple or branched tubular variety, being lined. by epithelium continuous with and similar to that of the surface. The stroma, according to most author:, consists of a delicate reticular network of fibrillar connective tissue containing in its meshes large numbers of round, oval, or spindle-shaped cells. At the present time there is no unanimity of opinion as to the exact nature of the stromal tissue. $\mathrm{Nagel}^{2}$ and Waldeyer ${ }^{3}$ believe it to be of a lymphoid type and compared it to the stroma of the intestinal mucosa. Leopold ${ }^{4}$ regarded it as a spread-out lymph gland (Lymphdrüsenfläche), while Johnstone ${ }^{5}$ believes that it is of an adenoid type. Most of the best authorities, however, accept the view of Minot, that the stroma is merely a form of embryonic connective tissue, and this is probably the correct one.

From a physiologic standpoint the endometrium bears an important relation, whether active or passive, to the function of menstruation, and it would be interesting, if time permitted, to trace the various views which have

1. Monatsh. f. Geburtsh. u. Gynäk., 1908, xxvil. 1.

2. von Bardeleben: Handbuch der Anatomie des Menschen.

3. Quoted by Williams: Text-Book on Obstetrics.

4. Arch. f. Gynäk., xí.

5. Brit. Gynæc. Jour., November, 1886. 